\title{
Solving Reactive Power Scheduling Problem using Multi-objective Crow Search Algorithm
}

\author{
Surender Reddy Salkuti \\ Department of Railroad and Electrical Engineering, Woosong University \\ Daejeon, Republic of Korea
}

\begin{abstract}
This paper presents the solution of multi-objective based optimal reactive power dispatch (MO-ORPD) problem by optimizing the system power losses and voltage stability enhancement index (VSEI)/L-index objectives. ORPD problem is considered as an important issue from system security and operational point of view for optimal steady-state operation of power system. Here, single-objective based ORPD problem is solved using Crow Search Algorithm (CSA) and multi-objective based ORPD problem is solved using multi-objective CSA (MOCSA). The CSA is considered as an efficient and robust algorithm which determines the global optimal solution for solving the non-linear and discontinuous objective functions. Two standard test systems, i.e., IEEE 30 and 57 bus systems are considered to show the effectiveness, suitability and robustness of CSA and MO-CSA for solving the ORPD problem.
\end{abstract}

Keywords-Optimal power flow; crow search algorithm; evolutionary algorithms; loss minimization; reactive power scheduling; multi-objective optimization

\section{NOMENCLATURE}

$N_{l} \quad$ Number of lines

$G_{k} \quad$ Conductance of $\mathrm{k}^{\text {th }}$ line

$N_{B} \quad$ Number of buses

$N_{G} \quad$ Number of generator/PV buses.

$Q_{G i} \quad$ Reactive power generation from the generator and VAR source at $\mathrm{i}^{\text {th }}$ bus

$Q_{D i} \quad$ Reactive power demand at $\mathrm{i}^{\text {th }}$ bus

$P_{G i} \quad$ Power generation at $\mathrm{i}^{\text {th }}$ bus

$N_{c} \quad$ Number of switchable capacitors/VAR sources.

$P_{i n j, i} \quad$ Active power injection at $\mathrm{i}^{\text {th }}$ bus

$Q_{\text {inj,i }} \quad$ Reactive power injection at $\mathrm{i}^{\text {th }}$ bus

$N_{L} \quad$ Number of load buses

$N_{T} \quad$ Number of tap changing transformers

$S_{L i} \quad$ Apparent power flowing through $\mathrm{i}^{\text {th }}$ transmission line

\section{INTRODUCTION}

Solution to the optimal reactive power dispatch (ORPD)/scheduling is required to meet the load demands at the nominal frequency as the reactive powers to maintain nominal voltage throughout the system. The ORPD is required to obtain secured, efficient and reliable operating condition of power system. Reactive power is localized to the point where the voltage needs regulating. Generally controlling of generator voltages is done automatically at corresponding generation power plant location. Series and shunt reactive devices are on the grid also provides the required local corrections. The energy management system of power system processes the raw data to provide reliable data base for the analysis of the power network [1]. Basically it includes topology processing and state estimation. Topology processing unit uses the dynamic status of the switches, i.e. breakers and isolators, to translate the network model into a node branch representation that can be analyzed by matrix methods. State estimation calculates the complex bus voltages and branch flows using the network model parameters, and values telemetered via Supervisory Control and Data Acquisition. The state estimator output provides a reliable database for other analysis applications such as optimal power flow (OPF), ORPD, etc. From planning perspective, the OPF is used for various applications for the shunt volt ampere reactive (VAR) planning [2], transfer capability studies, series capacitor planning, loss optimization studies, and reactive interchange studies. The literature related to ORPD problem is described next.

\section{A. Literature Review}

Review of various optimization approaches developed for the solution and analysis of ORPD with the main goal of enhancing efficiency, performance and security of power system is presented in [3]. The author in [4] solves the ORPD problem with voltage stability enhancement, and power loss, voltage deviation minimizations using the evolutionary based Artificial Bee Colony (ABC) algorithm. The author in [5] solves the ORPD problem using meta-heuristic based Crow Search Algorithm (CSA) and finds the optimal control variables settings. An enhanced and efficient differential evolution (DE) with new mutation approach is described in [6, 7] to solve ORPD problem with HVDC transmission link. A methodology based on entropy evolution approach is proposed in [8] using Gravitational Search technique and fractional particle swarm optimization (PSO) for the solution of ORPD problem. The author in [9] proposes the solution to ORPD considering the system losses and voltage deviation minimization as objectives. A mathematical model of ORPD considering the energy loss minimization at the costs of adjusting control equipment and the current time interval is proposed in [10]. 
The author in [11] solves the ORPD problem using the marine predators' algorithm by handling uncertainties concerning to the output of solar, wind units and load demand. Differential evolution (DE) based productive stochastic search approach for solving the ORPD problem is presented in [12]. A fractional evolutionary based method that achieves the objectives of ORPD problem by including the FACTS controllers is presented in [13]. The author in [14] proposes a stochastic fractal search methodology for the solution of ORPD problem considering the voltage stability index (VSI), voltage deviation and power losses objectives. A Levy Interior Search technique is proposed in [15] for the solution of multiobjective (MO) based ORPD problem. A two-step based methodology for the solution of MO based ORPD problem is proposed in [16].

\section{B. Motivation and Contribution}

From literature review section, it can be concluded that there is a research gap for solving the single and multiple objective based ORPD problems and determining the global optimal solution using the multi-objective based CSA. The conflicting nature of the system power loss and voltage stability margins, when treated as objective functions in the ORPD problem reveal that these objective functions shouldn't be treated independently. When the power system efficiency, security, and reliability are of equal concern, the two considered important and conflicting objectives are to be minimized simultaneously using multi-objective optimization (MOO) techniques. This provided motivation to use MO based CSA for simultaneous optimization of two conflicting ORPD objectives. The major contributions of this work are:

- ORPD is formulated as a non-linear, discrete optimization problem which is solved by using evolutionary based crow search algorithm (CSA).

- ORPD problem is solved considering minimizations of power losses and L-index objectives.

- The proposed problem with these two important and conflicting objectives must be solved using the MOO techniques. In this work, multi-objective CSA is used as a MOO algorithm.

- The solution of ORPD problem has been tested on IEEE 30 and 57 bus systems.

- Obtained results depict robustness, effectiveness and superiority over the other algorithms reported in the literature.
The remainder of this work is arranged as: Mathematical modeling of ORPD is illustrated in Section II. Section III describes the simulation results on two standard systems. Section IV summarizes the contributions and conclusions of this paper.

\section{PROBLEM FORMULATION}

The goal of ORPD is to set optimal values to the settings of control variables such that optimal values of objective function can be met. The control variables considered for this ORPD are the voltage magnitudes of generator buses, tap settings of transformers and reactive power generation from switchable VAR/capacitor banks [17]. Fig. 1 depicts the control variables considered in the proposed ORPD problem. ORPD is solved initially as single-objective optimization (SOO) problem by selecting each objective independently, and then it is solved as MOO problem by selecting all objectives simultaneously [18]. Here, two distinct objectives are selected for solving ORPD problem and they are presented below:

\section{A. Objective 1: Power Loss Minimization}

For the ORPD problem, minimization of power loss is selected as an objective $\left(J_{1}\right)$, and it is a non-linear function of system bus voltages and phase angles [19]. This objective function can be expressed as,

$J_{1}=P_{\text {loss }}=\sum_{k=1}^{N_{l}} G_{k}\left[V_{i}^{2}+V_{j}^{2}-2 V_{i} V_{j} \cos \left(\delta_{i}-\delta_{j}\right)\right]$

The above power loss equation can be rewritten as,

$J_{1}=P_{\text {loss }}=\frac{1}{2} \sum_{\substack{i=1, i \neq j}}^{N_{B}} \sum_{j=1}^{N_{B}} G_{i j}\left[V_{i}^{2}+V_{j}^{2}-2 V_{i} V_{j} \cos \left(\delta_{i}-\right.\right.$ $\left.\left.\delta_{j}\right)\right](2)$

\section{B. Objective 2: Voltage Stability Enhancement Index (VSEI)/ L-Index Minimization}

For the ORPD problem, the L-index is selected as another objective $\left(J_{2}\right)$ and it utilizes the information from general load flow (LF) solution. L-index is determined at all the load buses, and it illustrates proximity of power system to the point of voltage collapse [20]. L-index is determined by,

$$
L_{j}=\left|1-\sum_{i=1}^{N_{G}} \overline{F_{J l}} \frac{E_{i}}{E_{j}}\right| \quad j=N_{G}+1, \ldots, N_{B}
$$

In equation (3), the $\overline{F_{\jmath l}}$ values are determined from the $\left[Y_{\text {Bus }}\right]$ as,

$\left[\begin{array}{l}\overline{I^{G}} \\ \overline{I^{L}}\end{array}\right]=\left[\begin{array}{ll}\overline{Y^{G G}} & \overline{Y^{G L}} \\ \overline{Y^{L G}} & \overline{Y^{L L}}\end{array}\right]\left[\begin{array}{c}E_{G} \\ E_{L}\end{array}\right]$

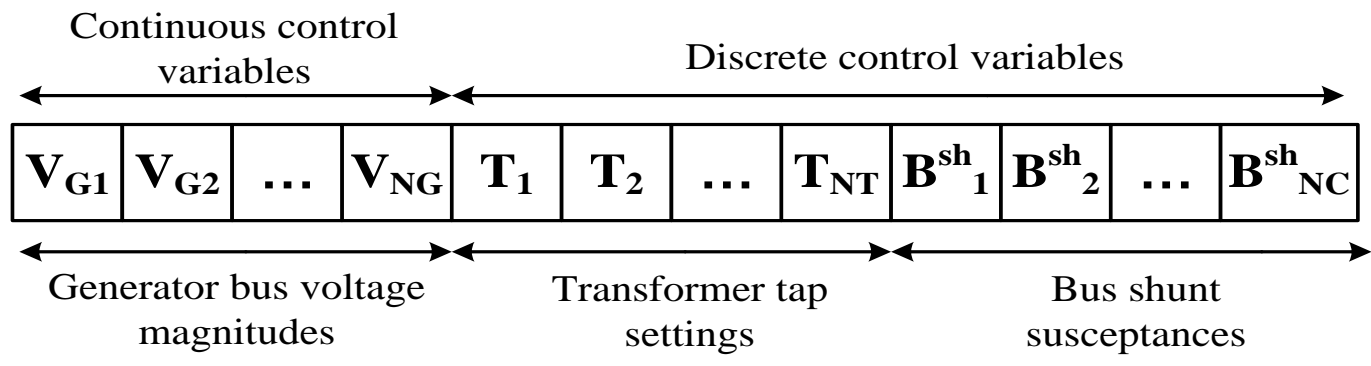

Fig. 1. Control Variables Considered in ORPD Problem. 
Where $E_{G}, E_{L}, \overline{I^{G}}, \bar{I}^{L}$ are voltage and current at generator and load nodes respectively. Rearranging the above equation [21],

$\left[\begin{array}{c}E_{L} \\ \overline{I^{G}}\end{array}\right]=\left[\begin{array}{ll}\overline{Z^{L L}} & \overline{F^{L G}} \\ \overline{K^{G L}} & \overline{Y^{G G}}\end{array}\right]\left[\begin{array}{l}\overline{I^{L}} \\ E_{G}\end{array}\right]$

This method is based on calculation of $\left.\mid \overline{F^{L G}}\right]$, which is obtained after reordering the generator and load buses. Where

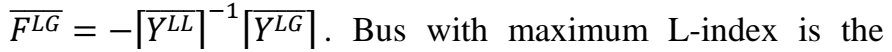
suitable location for the reactive compensation [22]. This minimization of L-index objective can be formulated as sum of squared values of L-indices, and it can be expressed as,

$J_{2}=\mathrm{VSEI}=\sum_{j=N_{G}+1}^{N_{B}} L_{j}^{2}$

\section{Equality Constraints}

These are general load flow (LF) expressions, and they are represented by [23],

$P_{G i}-P_{D i}=P_{i n j, i}=$

$V_{i} \sum_{j=1}^{N_{B}} V_{j}\left[G_{i j} \cos \delta_{i j}+B_{i j} \sin \delta_{i j}\right] \quad i=1,2, \ldots, N_{B}$

$Q_{G i}-Q_{D i}=Q_{i n j, i}=$

$V_{i} \sum_{j=1}^{N_{B}} V_{j}\left[G_{i j} \sin \delta_{i j}-B_{i j} \sin \delta_{i j}\right] \quad i=1,2, \ldots, N_{B}$

Where $Y_{i j}=G_{i j}+j B_{i j}$.

\section{Inequality Constraints}

They represent the operational and technical limits on the power network.

1) Generator constraints: The amount of power output from generators must be within the specific limits [24, 25] and they can be expressed as,

$\begin{array}{ll}P_{G i}^{\min } \leq P_{G i} \leq P_{G i}^{\max } & i=1,2,3, \ldots, N_{G} \\ Q_{G i}^{\min } \leq Q_{G i} \leq Q_{G i}^{\max } & i=1,2,3, \ldots, N_{G}\end{array}$

Voltage magnitudes of generators are limited by [26],

$V_{G i}^{\min } \leq V_{G i} \leq V_{G i}^{\max } \quad i=1,2,3, \ldots, N_{G}$

Where 'min' and 'max' represent the lower and upper limits of respective variables.

2) Reactive power source/switchable VAR source constraintsL: This constraint is limited by VAR source capacity limit [27] and it can be expressed as,

$Q_{c i}^{\min } \leq Q_{c i} \leq Q_{c i}^{\max } \quad i=1,2, \ldots, N_{c}$

3) Transformer constraints: The transformer tap position is limited by [28],

$T_{i}^{\min } \leq T_{i} \leq T_{i}^{\max } \quad i=1,2, \ldots, N_{T}$

4) Security constraints: The limits on voltage magnitudes of load buses and transmission lines are considered as security constraints [29, 30], and they are expressed as,

$V_{L i}^{\min } \leq V_{L i} \leq V_{L i}^{\max } \quad i=1,2, \ldots, N_{L}$
$S_{L i} \leq S_{L i}^{\max } \quad i=1,2, \ldots, N_{l}$

In this work, the SOO based ORPD problems are solved by using crow search algorithm (CSA), and MOO based ORPD problems are solved by using MO-CSA. Description of CSA and MO-CSA is presented in [31]-[33]. The detailed flow chart of MO-CSA is shown in Fig. 2.

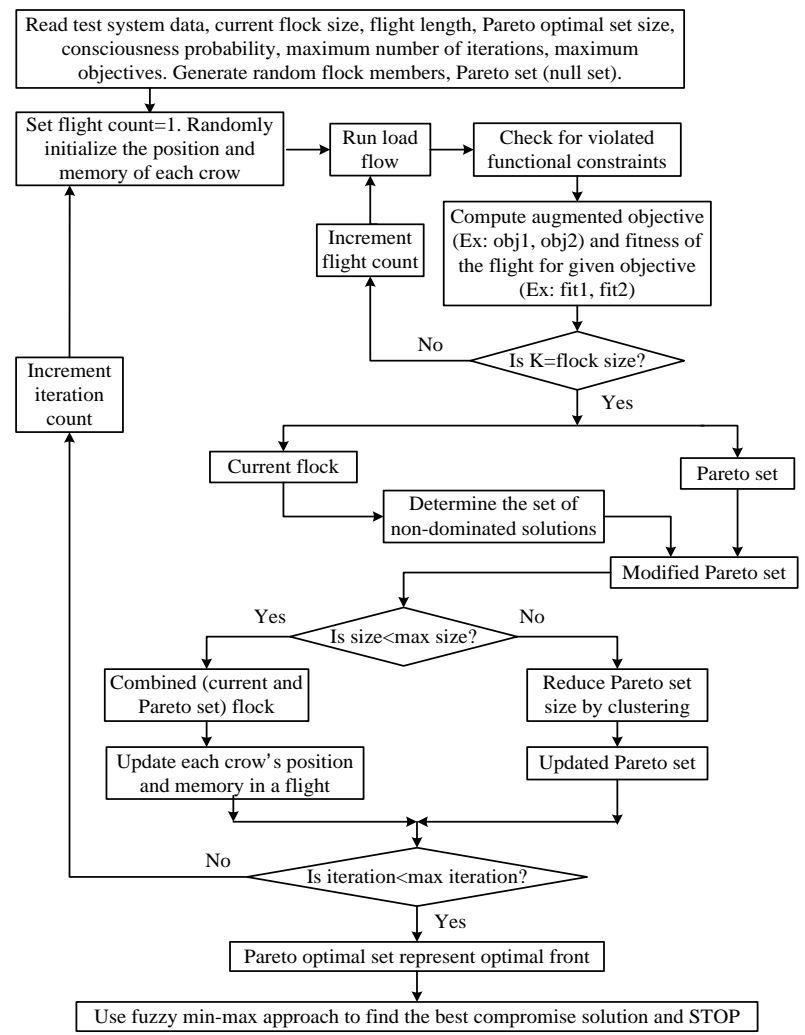

Fig. 2. Flow Chart of the MO-CSA.

\section{RESUltS AND DISCUSSION}

In this paper, to show the robustness and performance of proposed ORPD problem, CSA and MO-CSA algorithms are used and they are examined on IEEE 30 bus and 57 bus systems [34-37]. In this ORPD problem, voltages at generator buses, settings of transformer taps and values of shunt capacitance are considered as control variables. Here, three cases are implemented, and they are:

- Case 1: System power loss minimization

- Case 2: L-index/ VSEI minimization

- Case 3: Simultaneous optimization of active power losses and L-index

\section{A. Simulation Results on 30 Bus System}

This system has 6 generator/PV buses, 24 demands, 41 lines, 4 tap changing transformers and 9 shunt capacitance/compensation buses. In this test system, 19 control variables ( 6 voltage magnitudes of generator buses, 4 tap changing transformers and 9 bus shunt capacitance) are considered. Lower and upper limits of generator bus voltages, tap settings and shunt susceptance are $(0.95 \mathrm{pu}$ and $1.1 \mathrm{pu})$, (0.9 pu and $1.1 \mathrm{pu})$, and (0.0 pu and $0.05 \mathrm{pu})$. 
TABLE I. SETTINGS OF CONTROL VARIABLES FOR 30 BUS SYSTEM

\begin{tabular}{|c|c|c|c|c|c|c|c|c|c|}
\hline \multirow{3}{*}{$\begin{array}{l}\text { Control } \\
\text { variables }\end{array}$} & \multicolumn{8}{|c|}{ Single Objective Optimization (SOO) } & \multirow{3}{*}{$\begin{array}{l}\text { MOO } \\
\text { Case } 3 \\
\text { MO-CSA }\end{array}$} \\
\hline & \multicolumn{4}{|l|}{ Case 1} & \multicolumn{4}{|l|}{ Case 2} & \\
\hline & GA & GSA & DE & CSA & GA & PSO & DE & CSA & \\
\hline $\mathrm{V}_{\mathrm{G} 1}(\mathrm{pu})$ & 1.0 & 1.07165 & 1.1 & 1.0926 & 1.045 & 1.052 & 1.0511 & 1.0532 & 1.0853 \\
\hline $\mathrm{V}_{\mathrm{G} 2}(\mathrm{pu})$ & 0.999 & 1.02219 & 1.0944 & 1.0815 & 1.0573 & 1.034 & 1.0345 & 1.0465 & 1.0619 \\
\hline $\mathrm{V}_{\mathrm{G} 5}(\mathrm{pu})$ & 0.974 & 1.04 & 1.0749 & 1.0629 & 1.0718 & 1.0465 & 1.0426 & 1.0356 & 1.0562 \\
\hline $\mathrm{V}_{\mathrm{G} 8}(\mathrm{pu})$ & 1.007 & 1.0507 & 1.0768 & 1.0532 & 1.0423 & 1.0321 & 1.0415 & 1.0422 & 1.0485 \\
\hline $\mathrm{V}_{\mathrm{G} 11}(\mathrm{pu})$ & 1.0894 & 0.97712 & 1.0999 & 1.0986 & 1.0250 & 1.0252 & 1.0326 & 1.0624 & 1.0826 \\
\hline $\mathrm{V}_{\mathrm{G} 13}(\mathrm{pu})$ & 1.088 & 0.96765 & 1.0999 & 1.0413 & 1.045 & 1.0563 & 1.0442 & 1.0315 & 1.0385 \\
\hline $\mathrm{T}_{6,9}(\mathrm{pu})$ & NA & 1.0984 & 1.0465 & 1.05 & 0.925 & 0.90 & 0.95 & 0.925 & 0.9375 \\
\hline $\mathrm{T}_{6,10}(\mathrm{pu})$ & NA & 0.9824 & 0.9097 & 0.9875 & 0.9875 & 0.95 & 1.0125 & 0.9375 & 0.9875 \\
\hline $\mathrm{T}_{4,12}(\mathrm{pu})$ & NA & 1.0959 & 0.9867 & 1.0215 & 1.0215 & 0.9875 & 1.025 & 0.9875 & 1.025 \\
\hline $\mathrm{T}_{28,27}(\mathrm{pu})$ & NA & 1.0593 & 0.9689 & 1.075 & 1.05 & 1.075 & 0.95 & 1.025 & 1.0625 \\
\hline $\mathrm{b}_{\text {sh10 }}(\mathrm{pu})$ & NA & 0.016537 & 0.05 & 0.04 & 0.04 & 0.02 & 0.04 & 0.05 & 0.03 \\
\hline $\mathrm{b}_{\mathrm{sh} 12}(\mathrm{pu})$ & NA & 0.043722 & 0.05 & 0.05 & 0.03 & 0.05 & 0.05 & 0.03 & 0.04 \\
\hline $\mathrm{b}_{\text {sh15 }}(\mathrm{pu})$ & NA & 0.01199 & 0.05 & 0.05 & 0.04 & 0.03 & 0.03 & 0.03 & 0.05 \\
\hline $\mathrm{b}_{\mathrm{sh} 17}(\mathrm{pu})$ & NA & 0.020876 & 0.05 & 0.05 & 0.05 & 0.04 & 0.03 & 0.05 & 0.04 \\
\hline $\mathrm{b}_{\mathrm{sh} 20}(\mathrm{pu})$ & NA & 0.03577 & 0.04406 & 0.03 & 0.04 & 0.03 & 0.03 & 0.04 & 0.03 \\
\hline $\mathrm{b}_{\mathrm{sh} 21}(\mathrm{pu})$ & NA & 0.02602 & 0.05 & 0.02 & 0.03 & 0.04 & 0.04 & 0.03 & 0.04 \\
\hline $\mathrm{b}_{\text {sh23 }}(\mathrm{pu})$ & NA & 0.0 & 0.028004 & 0.04 & 0.02 & 0.03 & 0.05 & 0.02 & 0.05 \\
\hline $\mathrm{b}_{\mathrm{sh} 24}(\mathrm{pu})$ & NA & 0.013839 & 0.05 & 0.05 & 0.05 & 0.03 & 0.02 & 0.04 & 0.04 \\
\hline $\mathrm{b}_{\mathrm{sh} 29}(\mathrm{pu})$ & NA & 0.03 & 0.025979 & 0.03 & 0.05 & 0.04 & 0.03 & 0.05 & 0.03 \\
\hline $\begin{array}{l}\text { Power loss } \\
\text { (MW) }\end{array}$ & 4.2716 & 4.5143 & 4.555 & 4.1023 & --- & --- & --- & 6.724 & 4.927 \\
\hline VSEI & --- & --- & --- & 0.1298 & 0.1134 & 0.1105 & 0.1126 & 0.1103 & 0.1188 \\
\hline
\end{tabular}

Table I shows optimal settings of control variables for 30 bus system. Here, first the loss minimization objective is optimized independently (i.e., Case 1) using the genetic algorithm (GA), DE, gravitational search algorithm (GSA) and CSA, and obtained results are presented in Table I [38-39]. The power loss obtained using CSA is 4.1023 MW and the obtained corresponding VSEI value is 0.1298. Later, the VSEI/L-index objective is optimized independently (i.e., Case 2) using GA, PSO, DE and CSA, and obtained results are reported in Table I. The optimum L-index value obtained by using the CSA is 0.1188, and obtained power loss value is 4.927 MW.

From these case studies, it is clear that when the power loss is minimized then L-index has been deviated from optimum, and vice-versa. Hence, these two objectives are optimized simultaneously (i.e., Case 3) by using the MO-CSA. Pareto optimal front (POF) obtained for Case 3 has been depicted in Fig. 3. The best-compromised solution can be determined from the POF using fuzzy satisfaction method, and it has system power loss of 4.927 MW, and L-index of 0.1188.

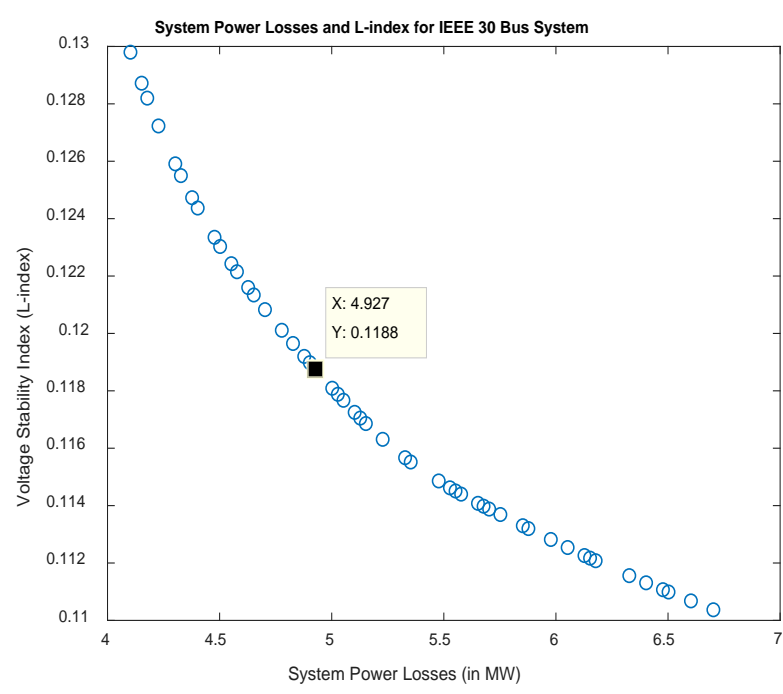

Fig. 3. Pareto Optimal Front for Case 3 of 30 Bus Systems. 


\section{B. Simulation Results on 57 Bus System}

This system has 7 PV buses, 42 loads, 80 lines, 15 tap changing transformers and 3 shunt capacitance/compensation buses. In this test system, 25 control variables ( 7 generator bus voltages, 15 tap changing transformers and 3 bus shunt capacitance) are considered. Lower and upper Minimum and maximum limits of generator bus voltages, tap settings and shunt susceptance are (0.95 pu and $1.1 \mathrm{pu}),(0.9 \mathrm{pu}$ and $1.1 \mathrm{pu})$, and $(0.0 \mathrm{pu}$ and $0.05 \mathrm{pu})$.

Table II shows optimal settings of controls for 57 bus system. Here, first the loss minimization objective is optimized independently (i.e., Case 1) using the GA, ABC, GSA and CSA, and the obtained results are reported in Table II.
The power loss obtained using CSA is 24.1022 MW and the obtained corresponding VSEI value is 0.1849 . Later, the VSEI/L-index objective is optimized independently (i.e., Case 2) by using GA, PSO and CSA, and the obtained values are reported in Table II [40-41]. The values of optimum L-index obtained by using CSA is 0.1363 , and obtained power loss value is $38.682 \mathrm{MW}$.

From these case studies, it is clear that when the power loss is optimized then L-index has been deviated from optimum value, and vice-versa. Hence, these two objectives are optimized simultaneously (i.e., Case 3 ) by using the MOCSA. The POF obtained for Case 3 has been depicted in Fig. 4. The trade-off solution can be obtained from the POF using fuzzy satisfaction method, and it has system power loss of 29.952 MW, and L-index of 0.1513.

TABLE II. SETTINGS OF CONTROL VARIABLES FOR 57 BUS SYSTEM

\begin{tabular}{|c|c|c|c|c|c|c|c|c|}
\hline \multirow{3}{*}{ Control variables } & \multicolumn{7}{|c|}{ Single Objective Optimization (SOO) } & \multirow{3}{*}{$\begin{array}{l}\text { MOO } \\
\text { Case } 3 \\
\text { MO-CSA }\end{array}$} \\
\hline & \multicolumn{4}{|c|}{ Case 1} & \multicolumn{3}{|l|}{ Case 2} & \\
\hline & GA & ABC & GSA & CSA & GA & PSO & CSA & \\
\hline $\mathrm{V}_{\mathrm{G} 1}(\mathrm{pu})$ & 1.06 & 1.0532 & 1.06 & 1.063 & 1.0712 & 1.0752 & 1.0786 & 1.0724 \\
\hline $\mathrm{V}_{\mathrm{G} 2}(\mathrm{pu})$ & 1.06 & 1.0587 & 1.0582 & 1.055 & 1.0685 & 1.0596 & 1.0652 & 1.0507 \\
\hline $\mathrm{V}_{\mathrm{G} 3}(\mathrm{pu})$ & 1.0483 & 1.052 & 1.0466 & 1.046 & 1.0567 & 1.0615 & 1.0451 & 1.0520 \\
\hline $\mathrm{V}_{\mathrm{G} 6}(\mathrm{pu})$ & 1.0423 & 1.0358 & 1.0409 & 1.021 & 1.0466 & 1.0590 & 1.0480 & 1.0477 \\
\hline $\mathrm{V}_{\mathrm{G} 8}(\mathrm{pu})$ & 1.06 & 1.0518 & 1.0587 & 1.053 & 1.0591 & 1.0620 & 1.0589 & 1.0535 \\
\hline $\mathrm{V}_{\mathrm{G} 9}(\mathrm{pu})$ & 1.0432 & 1.0436 & 1.0417 & 1.015 & 1.0488 & 1.0532 & 1.0674 & 1.0480 \\
\hline $\mathrm{V}_{\mathrm{G} 12}(\mathrm{pu})$ & 1.0387 & 1.0455 & 1.0377 & 1.064 & 1.0432 & 1.5589 & 1.0483 & 1.0551 \\
\hline $\mathrm{T}_{4,18}(\mathrm{pu})$ & 0.9 & 1.02 & 0.944 & 0.95 & 1.0 & 0.95 & 0.9875 & 0.925 \\
\hline $\mathrm{T}_{4,18}(\mathrm{pu})$ & 1.1 & 1.03 & 1.0182 & 0.9625 & 0.95 & 0.9125 & 0.9125 & 0.9875 \\
\hline $\mathrm{T}_{21,20}(\mathrm{pu})$ & 1.0314 & 0.95 & 1.0207 & 1.05 & 0.9125 & 0.9625 & 0.95 & 1.075 \\
\hline $\mathrm{T}_{24,26}(\mathrm{pu})$ & 1.0097 & 1.03 & 1.0110 & 1.0 & 0.9625 & 1.0 & 0.9 & 1.05 \\
\hline $\mathrm{T}_{7,29}(\mathrm{pu})$ & 0.9754 & 0.98 & 0.9744 & 0.9375 & 0.95 & 1.0125 & 1.05 & 0.9125 \\
\hline $\mathrm{T}_{34,32}(\mathrm{pu})$ & 0.9746 & 1.05 & 0.9721 & 0.9 & 0.925 & 1.0375 & 0.9625 & 0.9625 \\
\hline $\mathrm{T}_{11,41}(\mathrm{pu})$ & 0.9 & 0.95 & 0.9015 & 0.95 & 0.925 & 0.9875 & 0.9125 & 1.0375 \\
\hline $\mathrm{T}_{15,45}(\mathrm{pu})$ & 0.9726 & 0.98 & 0.9723 & 1.025 & 0.95 & 1.075 & 0.9875 & 0.975 \\
\hline $\mathrm{T}_{14,46}(\mathrm{pu})$ & 0.9538 & 0.96 & 0.9537 & 1.0 & 0.9125 & 0.9125 & 1.0125 & 0.9625 \\
\hline $\mathrm{T}_{10,51}(\mathrm{pu})$ & 0.9680 & 0.99 & 0.9664 & 0.9875 & 1.075 & 1.0625 & 1.05 & 1.0375 \\
\hline $\mathrm{T}_{13,49}(\mathrm{pu})$ & 0.9264 & 1.04 & 0.9269 & 1.025 & 0.9 & 0.9875 & 1.1 & 1.05 \\
\hline $\mathrm{T}_{11,43}(\mathrm{pu})$ & 1.1 & 1.08 & 0.9645 & 0.95 & 0.95 & 0.9125 & 1.0375 & 0.9125 \\
\hline $\mathrm{T}_{40,56}(\mathrm{pu})$ & 1.0624 & 0.99 & 0.9943 & 1.0125 & 1.075 & 1.05 & 0.95 & 0.9625 \\
\hline $\mathrm{T}_{39,57}(\mathrm{pu})$ & 1.0265 & 0.97 & 0.9737 & 0.9875 & 1.0 & 0.925 & 0.975 & 0.975 \\
\hline $\mathrm{T}_{9,55}(\mathrm{pu})$ & 0.9764 & 1.02 & 0.9750 & 0.95 & 0.9125 & 0.975 & 0.9875 & 1.0625 \\
\hline $\mathrm{b}_{\text {sh18 }}(\mathrm{pu})$ & 0.0999 & 0.0785 & 0.0928 & 0.05 & 0.03 & 0.05 & 0.05 & 0.03 \\
\hline $\mathrm{b}_{\mathrm{sh25}}(\mathrm{pu})$ & 0.059 & 0.05656 & 0.0589 & 0.04 & 0.04 & 0.05 & 0.04 & 0.03 \\
\hline $\mathrm{b}_{\text {sh53 }}(\mathrm{pu})$ & 0.063 & 0.04953 & 0.0628 & 0.05 & 0.04 & 0.04 & 0.02 & 0.05 \\
\hline Power loss (MW) & 24.3826 & 24.1025 & 24.2619 & 24.1022 & 38.247 & 38.584 & 38.682 & 29.952 \\
\hline VSEI & 0.1846 & --- & --- & 0.1849 & 0.1422 & 0.1408 & 0.1363 & 0.1513 \\
\hline
\end{tabular}




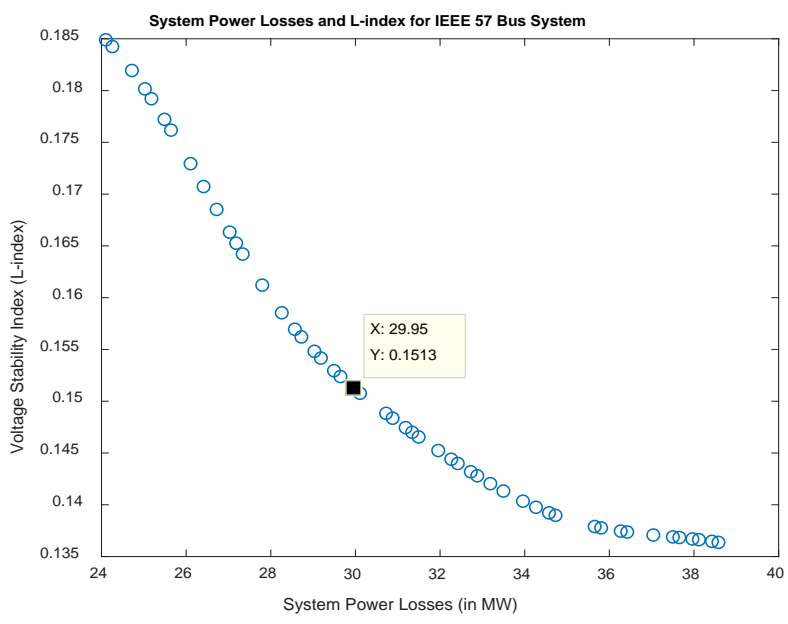

Fig. 4. Pareto Optimal Front for Case 3 of IEEE 57 Bus System.

\section{CONCLUSIONS}

This paper proposed solution to the multi-objective based nonlinear, discrete ORPD problem. System power losses and L-index/VSEI are selected as objective functions, and they are solved by using the CSA. This work also considers the discrete variables, i.e., settings of transformer taps and switchable VAR/shunt capacitors. For this ORPD problem, these two objectives are observed as the two conflicting objectives and there is a need to solve these two objectives jointly. Therefore, the MO-CSA algorithm is used to solve this multi-objective ORPD problems. The proposed MO-CSA gives the Pareto optimal set with the trade-off/bestcompromised solutions, in a single run. System operator selects one trade-off solution using the higher level information or by fuzzy satisfaction method. The solution of ORPD problem gives optimum values of objective function and control variable values. The proposed CSA and MO-CSA algorithms are examined on 30 and 57 bus systems. The obtained results depict the robustness, superiority, and effectiveness over other algorithms reported in the literature.

\section{ACKNOWLEDGMENT}

This research work was funded by "Woosong University's Academic Research Funding - 2021”.

\section{REFERENCES}

[1]. K. Nuaekaew, P. Artrit, N. Pholdee, S. Bureerat, “Optimal reactive power dispatch problem using a two-archive multi-objective grey wolf optimizer”, Expert Systems with Applications, vol. 87, pp. 79-89, 2017.

[2]. N. Wang, J. Li, X. Yu, D. Zhou, W. Hu, Q. Huang, Z. Chen, F. Blaabjerg, "Optimal active and reactive power cooperative dispatch strategy of wind farm considering levelised production cost minimization”, Renewable Energy, vol. 148, pp. 113-123, 2020.

[3]. Y. Muhammad, R. Khan, M.A.Z. Raja, F. Ullah, N.I. Chaudhary, Y. He, "Solution of optimal reactive power dispatch with FACTS devices: A survey”, Energy Reports, vol. 6, pp. 2211-2229, 2020.

[4]. M. Ettappan, V. Vimala, S. Ramesh, V.T. Kesavan, Optimal reactive power dispatch for real power loss minimization and voltage stability enhancement using Artificial Bee Colony Algorithm, Microprocessors and Microsystems, vol. 76, 2020.

[5]. M. Lakshmi, A. Ramesh Kumar, “Optimal Reactive Power Dispatch using Crow Search Algorithm”, International Journal of Electrical and Computer Engineering (IJECE), vol. 8, no. 3, pp. 1423-1431, Jun. 2018.
[6]. M.A.M. Shaheen, H.M. Hasanien, A. Alkuhayli, “A novel hybrid GWOPSO optimization technique for optimal reactive power dispatch problem solution”, Ain Shams Engineering Journal, vol. 12, no. 1, pp. 621-630, 2021.

[7]. S. Sayah, "Modified differential evolution approach for practical optimal reactive power dispatch of hybrid AC-DC power systems", Applied Soft Computing, vol. 73, pp. 591-606, 2018.

[8]. R. Jamal, B. Men, N.H. Khan, M.A.Z. Raja, Y. Muhammad, "Application of Shannon Entropy Implementation Into a Novel Fractional Particle Swarm Optimization Gravitational Search Algorithm (FPSOGSA) for Optimal Reactive Power Dispatch Problem”, IEEE Access, vol. 9, pp. 2715-2733, 2021.

[9]. N.H. Khan, Y. Wang, D. Tian, M.A.Z. Raja, R. Jamal, Y. Muhammad, "Design of Fractional Particle Swarm Optimization Gravitational Search Algorithm for Optimal Reactive Power Dispatch Problems”, IEEE Access, vol. 8, pp. 146785-146806, 2020.

[10]. Y. Zhang, Z. Ren, “Optimal reactive power dispatch considering costs of adjusting the control devices", IEEE Transactions on Power Systems, vol. 20, no. 3, pp. 1349-1356, Aug. 2005.

[11]. M. Ebeed, A. Alhejji, S. Kamel, F. Jurado, "Solving the Optimal Reactive Power Dispatch Using Marine Predators Algorithm Considering the Uncertainties in Load and Wind-Solar Generation Systems”, Energies, vol. 13, 2020.

[12]. V. Suresh, S.S. Kumar, "Optimal reactive power dispatch for minimization of real power loss using SBDE and DE-strategy algorithm”, Journal of Ambient Intelligence and Humanized Computing, 2020.

[13]. Y. Muhammad, R. Akhtar, R. Khan, F. Ullah, M.A.Z. Raja, J.A.T. Machado, "Design of fractional evolutionary processing for reactive power planning with FACTS devices”, Scientific Reports, vol. 11, 2021.

[14]. T.L. Duong, M.Q. Duong, V.D. Phan, T.T. Nguyen, “Optimal Reactive Power Flow for Large-Scale Power Systems Using an Effective Metaheuristic Algorithm", Journal of Electrical and Computer Engineering, vol. 2020, pp. 1-11, 2020.

[15]. K. Nagarajan, A.K. Parvathy, A. Rajagopalan, "Multi-Objective Optimal Reactive Power Dispatch using Levy Interior Search Algorithm”, International Journal on Electrical Engineering and Informatics, vol. 12, no. 3, pp. 547-570, Sept. 2020.

[16]. M. Zhang, Y. Li, "Multi-Objective Optimal Reactive Power Dispatch of Power Systems by Combining Classification-Based Multi-Objective Evolutionary Algorithm and Integrated Decision Making”, IEEE Access, vol. 8, pp. 38198-38209, 2020.

[17]. M. Basu, "Multi-objective optimal reactive power dispatch using multiobjective differential evolution”, International Journal of Electrical Power \& Energy Systems, vol. 82, pp. 213-224, 2016.

[18]. M.S. Saddique, A.R. Bhatti, S.S. Haroon, M.K. Sattar, S. Amin, I.A. Sajjad, S.S. Haq, A.B. Awan, N. Rasheed, "Solution to optimal reactive power dispatch in transmission system using meta-heuristic techniques-Status and technological review", Electric Power Systems Research, vol. 178, 2020.

[19]. S. Jaiswal, T. Ghose, "Optimal real power dispatch of centralized microgrid control operation”, International Conference on Circuit ,Power and Computing Technologies (ICCPCT), Kollam, India, 2017, pp. 1-7.

[20]. M. Hashemi, M.H. Zarif, “A novel hierarchical distributed framework for optimal reactive power dispatch based on a system of systems structure”, Computers \& Electrical Engineering, vol. 78, pp. 162-183, 2019.

[21]. M. Alramlawi, E. Mohagheghi, P. Li, "Predictive active-reactive optimal power dispatch in PV-battery-diesel microgrid considering reactive power and battery lifetime costs”, Solar Energy, vol. 193, pp. 529-544, 2019.

[22]. P.P. Biswas, P.N. Suganthan, R. Mallipeddi, G.A.J. Amaratunga, "Optimal reactive power dispatch with uncertainties in load demand and renewable energy sources adopting scenario-based approach”, Applied Soft Computing, vol. 75, pp. 616-632, 2019.

[23]. SK.M. Shareef, R.S. Rao, "Optimal reactive power dispatch under unbalanced conditions using hybrid swarm intelligence”, Computers \& Electrical Engineering, vol. 69, pp. 183-193, 2018. 
[24]. R.N.S. Mei, M.H. Sulaiman, Z. Mustaffa, H. Daniyal, “Optimal reactive power dispatch solution by loss minimization using moth-flame optimization technique”, Applied Soft Computing, vol. 59, pp. 210-222, 2017.

[25]. J. Li, N. Wang, D. Zhou, W. Hu, Q. Huang, Z. Chen, F. Blaabjerg, "Optimal reactive power dispatch of permanent magnet synchronous generator-based wind farm considering levelised production cost minimization”, Renewable Energy, vol. 145, pp. 1-12, 2020.

[26]. A.M. Shaheen, R.A. El-Sehiemy, S.M. Farrag, "Optimal reactive power dispatch using backtracking search algorithm”, Australian Journal of Electrical and Electronics Engineering, vol. 13, no. 3, pp. 200-210, 2016.

[27]. S.R. Salkuti, "Optimal Reactive Power Scheduling Using Cuckoo Search Algorithm”, International Journal of Electrical and Computer Engineering, vol. 7, no. 5, pp. 2349-2356. Oct. 2017.

[28]. T.T. Nguyen, D.N. Vo, H.V. Tran, L.V. Dai, "Optimal Dispatch of Reactive Power Using Modified Stochastic Fractal Search Algorithm”, Complexity, vol. 2019, pp. 1-28, 2019.

[29]. Y. Zhang, C. Chen, C. Lee, "Solution of the optimal reactive power dispatch for power systems by using novel charged system search algorithm," 7th International Symposium on Next Generation Electronics (ISNE), Taipei, Taiwan, 2018, pp. 1-4.

[30]. P.K. Roy, S.P. Ghoshal, S.S. Thakur, “Optimal Reactive Power Dispatch Considering Flexible AC Transmission System Devices Using Biogeography-based Optimization”, Electric Power Components and Systems, vol. 39, no. 8, pp. 733-750, 2011.

[31]. A. Meddeb, N. Amor, M. Abbes, S. Chebbi, “A Novel Approach Based on Crow Search Algorithm for Solving Reactive Power Dispatch Problem”, Energies, vol. 11, 2018.

[32]. A. Saha, A. Bhattacharya, P. Das, A.K. Chakraborty, "Crow search algorithm for solving optimal power flow problem”, Second International Conference on Electrical, Computer and Communication Technologies (ICECCT), Coimbatore, 2017, pp. 1-8.
[33]. S.R. Salkuti, Multi-objective based Optimal Network Reconfiguration using Crow Search Algorithm, International Journal of Advanced Computer Science and Applications (IJACSA), vol. 12, no. 3, pp. 86-95, 2021.

[34]. S.S. Reddy, P.R. Bijwe, A.R. Abhyankar, "Faster Evolutionary Algorithm Based Optimal Power Flow using Incremental Power Flow Model”, International Journal of Electrical Power \& Energy Systems, vol. 54, pp. 198-210, 2014.

[35]. M.S. Kumari, S. Maheswarapu, "Enhanced Genetic Algorithm based computation technique for multi-objective Optimal Power Flow solution”, International Journal of Electrical Power \& Energy Systems, vol. 32, no. 6, pp. 736-742, 2010.

[36]. S.S. Reddy, P.R.Bijwe, "Differential evolution-based efficient multiobjective optimal power flow”, Neural Computing and Applications, vol. 31, no. 1, pp. 509-522, Jan. 2019.

[37]. M. Mehdinejad, B.M. Ivatloo, R.D. Bonab, K. Zare, "Solution of optimal reactive power dispatch of power systems using hybrid particle swarm optimization and imperialist competitive algorithms", International Journal of Electrical Power \& Energy Systems, vol. 83, pp 104-116, 2016.

[38]. S.R. Salkuti, “Optimal power flow using hybrid differential evolution and harmony search algorithm”, International Journal of Machine Learning and Cybernetics, vol. 10, no. 5 pp. 1077-1091, May 2019.

[39]. C.M. Huang, Y.C. Huang, “Combined Differential Evolution Algorithm and Ant System for Optimal Reactive Power Dispatch”, Energy Procedia, vol. 14, pp. 1238-1243, 2012.

[40]. S.S. Reddy, Ch.S. Rathnam, "Optimal Power Flow Using Glowworm Swarm Optimization”, International Journal of Electrical Power \& Energy Systems, vol. 80, pp. 128-139, 2016.

[41]. S. Mouassa, T. Bouktir, A. Salhi, "Ant lion optimizer for solving optimal reactive power dispatch problem in power systems", Engineering Science and Technology, an International Journal, vol. 20, no. 3, pp. 885-895, 2017. 